Note

\title{
Antimicrobial Activity of the Carnivorous Plant Dionaea muscipula Against Food-Related Pathogenic and Putrefactive Bacteria
}

\author{
HIROKAZU OGIHARA ${ }^{1 *}$, FUMIKO ENDOU ${ }^{1}$, SOICHI FURUKAWA', \\ HIROSHI MATSUFUJI ${ }^{1}$, KOUICHI SUZUKI ${ }^{1}$, AND HIROSHI ANZAI ${ }^{2}$ \\ ${ }^{1}$ Department of Food Bioscience and Biotechnology, College of Bioresource Sciences, \\ Nihon University, 1866 Kameino, Fujisawa, Kanagawa 252-0880, Japan \\ ${ }^{2}$ Department of Bioresource Science, Junior college, Nihon University, \\ 1866 Kameino, Fujisawa, Kanagawa 252-0880, Japan
}

Received 9 October, 2012/Accepted 13 January, 2013

\begin{abstract}
Solvent extracts from the carnivorous plant Dionaea muscipula (Venus flytrap) were prepared using eight different organic solvents, and examined for antibacterial activity against foodrelated pathogenic and putrefactive bacteria. All solvent extracts showed higher antibacterial activity against gram positive bacteria than against gram negative bacteria. The TLCbioautography analysis of the extracts revealed that a yellow spot was detected at $R f$ value of 0.85 , which showed strong antibacterial activity. The UV, MS, and NMR analyses revealed that the antibacterial compound was plumbagin.
\end{abstract}

Key words : Antimicrobial activity / Dionaea muscipula / Food-related borne pathogenic bacteria / Plumbagin / Carnivorous plant.

Recently, the bacteriostatic and bactericidal effects of functional ingredients in plants against microorganisms have been examined, particularly in plants such wasabi (Inouye et al., 1983), green tea (Toda et al., 1989), moso bamboo (Nishina and Uchibori., 1991), Job's Tears (Ishiguro et al., 1993), hops (Larson et al., 1996), persimmon leaves (Yamada et al., 1999), grapefruit peels (Negi and Jayaprakasha, 2001), grape seed (Jayaprakasha, et al., 2003), pomegranate peel (Negi and Jayaprakasha, 2003), Japanese basil (Vardar-Ünlü et al., 2003), flowers (Alzoreky and Nakahara., 2003), and cranberries (Wu et al., 2008). Some of them are used as food additives to increase the shelf life of food products.

Carnivorous plants are angiosperm spermatophytes (seed plants) and have acquired insectivorous behaviors. As many of these carnivorous plants grow in oligotrophic marshlands that are nitrogen deficient, these plants have developed the ability to trap insects

*Corresponding author. Tel\&Fax: +81-466-84-3972, E-mail : ogihara (a) brs. nihon-u.ac.jp and extract the nitrogen they require for growth and propagation (Juniper et al., 1989). Interestingly, despite coming into close contact with insects, carnivorous plants rarely become infected by the pathogenic bacteria transmitted by many insects, suggesting the presence of some sort of defense mechanism. Few studies have been conducted on antibacterial activity of carnivorous plants, although the inhibitory effects of carnivorous plant extracts on intestinal bacteria have been reported (Park et al., 2005).

Dionaea muscipula (Venus flytrap) is a well-known carnivorous plant that catches and digests insects and spiders, and is also popular as a cultivated plant. Based on the possibility that carnivorous plants may employ special antibacterial defense mechanisms, we examined the antibacterial activity of $D$. muscipula extracts against food-related pathogenic and putrefactive bacteria in this study.

Dionaea muscipula was cultivated from parent plants. Small pieces of plant tissue were taken and transferred to a Murashige and Skoog Plant Salt Mixture (Wako Pure Chemical Industries, Ltd., Osaka, Japan). The 
tissue samples were then cultured for approximately two months at room temperature. After removing dirt and impurities from the selected D. muscipula specimens, the plants were weighed, frozen in liquid nitrogen and ground using a mortar and pestle. Five grams of the ground tissue were added to $50 \mathrm{ml}$ of ethanol, methanol, acetone, methyl ethyl ketone, ethyl acetate, 2-propanol, chloroform and hexane, and extraction was performed by agitation for $24 \mathrm{~h}$ at $4^{\circ} \mathrm{C}$. Each extract was filtered, and then concentrated to 5 $\mathrm{ml}$ under vacuum.

The bacterial strains used in this study were the gram positive bacteria, Bacillus cereus IAM 1110, Bacillus subtilis ATCC 6633, Micrococcus luteus ATCC 9341, Staphylococcus aureus CSJ 1923 and Enterococcus faecalis ATCC $29212(n=5)$, and the gram negative bacteria, Escherichia coli CSJ 1922, Escherichia coli ATCC 35150 (O157:H7), Pseudomonas aeruginosa CSJ 1853, Salmonella Enteritidis IFO 3313, Salmonella Typhimurium IID 971, Serratia marcescens ATCC 13880 and Yersinia enterocolitica JCM $1677(n=7)$. All strains were incubated for $24 \mathrm{~h}$ at $37^{\circ} \mathrm{C}$, except $M$. luteus and $Y$. enterocolitica which were incubated at $30^{\circ} \mathrm{C}$.

First, we attempted to examine the antibacterial activity of the extracts. Assessments of the activity were conducted using a National Committee for Clinical Laboratory Standards disk diffusion method (NCCLS., 1990). Bacterial strains were subcultured in tryptic soy broth (TSB; Becton Dickinson Co. Franklin Lakes, $\mathrm{BJ}$, USA) at $30^{\circ} \mathrm{C}$ or $37^{\circ} \mathrm{C}$ for $24 \mathrm{~h}$ and then smeared on Mueller-Hinton Agar (MHA; Becton Dickinson Co. Franklin Lakes, BJ, USA). Colonies were then collected and used to prepare bacterial solutions with a McFarland turbidity of 0.5. These were then smeared on MHA plates with a sterile cotton swab before a paper disk (diameter $=6 \mathrm{~mm}$, Toyo Roshi Kaisha, Ltd. Tokyo, Japan) inoculated with $30 \mu \mathrm{I}$ of the extract was placed on the bacterial cultures. The MHA plates were then incubated at $30^{\circ} \mathrm{C}$ or $37^{\circ} \mathrm{C}$ for $18 \mathrm{~h}$ and the inhibition zone diameter was measured.

Table 1 summarizes the antibacterial activity of solvent extracts from $D$. muscipula. The antibacterial activity of each extract was assessed against the gram positive bacterium, S. aureus, and the gram negative bacterium, E. coli. All of the solvent extracts showed higher antibacterial activity against gram positive bacteria than against gram negative bacteria. Among them, the extracts with ethanol, acetone and chloroform showed large inhibition zones of $\geq 27 \mathrm{~mm}$ against $S$. aureus. Although the sizes of the inhibition zone against $E$. coli were smaller than those against $S$. aureus, methanol, ethanol, methyl ethyl ketone and 2-propanol extracts showed higher antibacterial activity than those of other extracts.
The components in the extracts were analyzed by using high performance thin layer chromatography (HPTLC). Silica gel $60 \mathrm{~F}_{254}$ with a $0.25 \mathrm{~mm}$ thickness $(10 \times 10 \mathrm{~cm}$, Merck Ltd., Darmstadt, Germany) was used for HPTLC analysis. Five to nine spots were observed in different solvent extracts, and some of them were detected at the same $R f$ values, although the amounts (spot size) were different depending on the solvent used (Fig. 1). These results implied that the common compounds observed in all solvent extracts, specifically the compounds detected at the same $R f$ values, may show antibacterial activity.

From the results of HPTLC analysis, the methanol and ethanol extracts contained several compounds, and therefore the antibacterial activity of these extracts was examined against various food-related bacteria (Table 2). When tested against five species of gram positive bacteria and seven species of gram negative bacteria, antibacterial activity was observed against all 12 test strains. Large inhibition zones measuring 29.0土 1.8 to $31.1 \pm 1.7 \mathrm{~mm}$ in diameter were observed around the gram positive bacteria (B. subtilis, M. luteus and $S$. aureus), indicating strong antibacterial activity. On the other hand, the inhibition zones around the gram negative bacteria were smaller ( $\leq 11 \mathrm{~mm}$ in diameter), indicating that these extracts were less effective against the test bacteria. Although no differences in the bactericidal efficacy between ethanol and methanol extracts were observed, the ethanol extract showed slightly larger inhibition zones.

The TLC-bioautography which combined microbial detection with TLC separation technique was used to assess the antibacterial activity of the separated spots. As shown in Fig. 2, the clear zone on the agar plate showed a $R f$ value of 0.85 , which appeared at the same position as the yellow spot observed in the HPTLC analysis, suggesting the presence of an antibacterial compound in the yellow spot.

TABLE 1. Antibacterial activity of Dionaea muscipula extracts against $S$. aureus and $E$. coli

\begin{tabular}{lcc}
\hline \multirow{2}{*}{ Each solvent } & \multicolumn{2}{c}{ Inhibition zone diameter $(\mathrm{mm})$} \\
\cline { 2 - 3 } & S. aureus & E. coli \\
\hline Methanol & ++ & ++ \\
Ethanol & +++ & ++ \\
2-propanol & ++ & ++ \\
Acetone & ++ & + \\
Ethyl acetate & +++ & + \\
Ethylmethylketone & ++ & ++ \\
Chroloform & +++ & + \\
Hexane & ++ & + \\
\hline
\end{tabular}

Each extracts $(30 \mu \mathrm{I})$ was used in paper disk (Inhibition zone, including diameter of the disk, $6.0 \mathrm{~mm}$ )

$+: \leqq 10 \mathrm{~mm},++:>10 \sim \leqq 27 \mathrm{~mm},+++$ : $>27 \mathrm{~mm}$ 


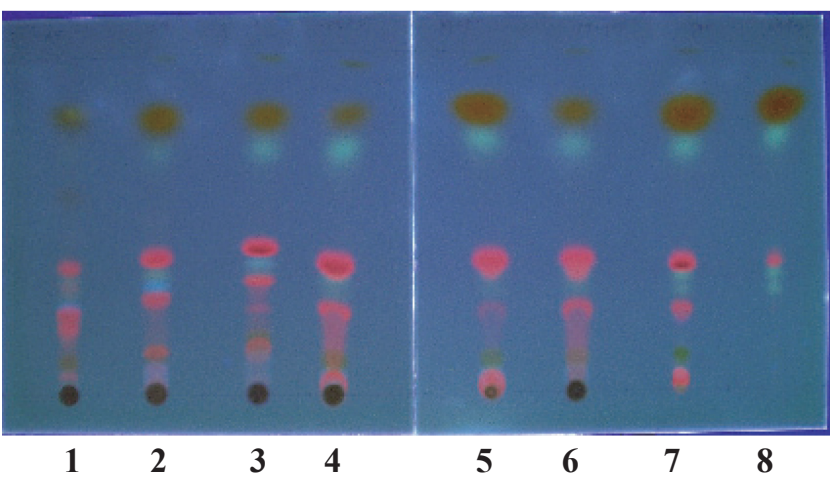

FIG. 1. HPTLC of different solvent extracts from Dionaea muscipula

1, methanol; 2, ethanol; 3, 2-propanol; 4, acetone; 5, ethyl acetate; 6 , ethyl methyl ketone; 7 , chloroform; 8 , hexane. The sample powder $(5 \mathrm{~g})$ was incubated with different solvents $(50 \mathrm{ml})$ at $4{ }^{\circ} \mathrm{C}$ for $24 \mathrm{~h}$. After filtration and evaporation, the evaporate was dissolved in each solvent $(5 \mathrm{ml})$. An aliquot $(10 \mu \mathrm{l})$ of the extract was withdrawn for HPTLC and spotted. The HPTLC was used with diethylether - hexane (1:1) as a developing solvent. The images were captured on a plate under UV light at $254 \mathrm{~nm}$.

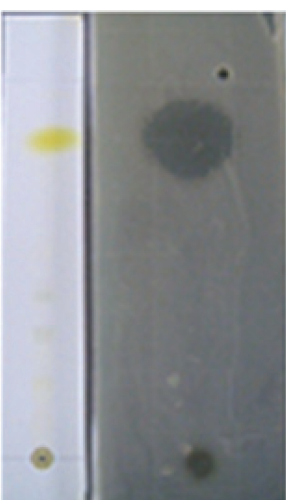

FIG. 2. TLC-bioautography of ethanol extract from Dionaea muscipula

The samples were directly deposited on the TLC plates (8 $\times 23 \mathrm{~cm}$, Eiken Chemical Co. Ltd., Tokyo, Japan), and then the TLC plates were developed with diethyl ether -hexane (1: $1, \mathrm{v} / \mathrm{v}$ ) as a developing solvent. Each TLC plate was gently placed face down for 15 min on a square Petri dish that contained MHA inoculated with B. subtilus ATCC 6633. After separating the TLC plate from the agar, the Petri dishes were incubated for $20 \mathrm{~h}$ at $37^{\circ} \mathrm{C}$. The antibacterial zone diameter was measured.

TABLE 2. Antibacterial activity of solvent extracts from Dionaea muscipula extracts against food-related pathogenic and putrefactive bacteria.

\begin{tabular}{clcc}
\hline \multirow{2}{*}{ Bacterial strains } & \multicolumn{2}{c}{ Inhibition zone diameter $(\mathrm{mm})$} \\
\cline { 2 - 4 } & B. cereus & Methanol & Ethanol \\
\hline \multirow{2}{*}{ Gram positive } & B. subtilis & $20.3 \pm 1.5$ & $20.9 \pm 1.7$ \\
bacteria & M. luteus & $29.0 \pm 1.8$ & $30.1 \pm 1.0$ \\
& S. aureus & $29.1 \pm 0.9$ & $30.5 \pm 1.9$ \\
& S. faecalis & $31.1 \pm 1.7$ & $30.9 \pm 1.2$ \\
Gram negative & E. coli & $18.8 \pm 0.5$ & $18.9 \pm 0.5$ \\
\hline bacteria & E. coli O157:H7 & $10.9 \pm 0.9$ & $10.8 \pm 0.7$ \\
& S. Enteritidis & $9.8 \pm 0.8$ & $10.2 \pm 0.7$ \\
& S. Typhimurium & $8.6 \pm 0.9$ & $8.2 \pm 0.7$ \\
& S. marcescens & $9.7 \pm 1.3$ & $10.2 \pm 0.4$ \\
& & $8.9 \pm 0.4$ & $9.5 \pm 0.2$ \\
\hline
\end{tabular}

Each extracts $(30 \mu \mathrm{I})$ was used in paper disk (Inhibition zone, including diameter of the disk, $6.0 \mathrm{~mm}$ )

To identify the antibacterial compound, preparative TLC and HPLC purifications and spectroscopic analyses were performed. The methanol extract $(400 \mathrm{ml})$ was prepared using $40 \mathrm{~g}$ of $D$. muscipula lyophilized powder as described above. After being concentrated to 40 $\mathrm{ml}$, the solutions were applied onto the preparative TLC plates (Silica gel 60, $20 \times 20 \mathrm{~cm}$, thickness 0.7 $\mathrm{mm}$, Merck Ltd.) using diethyl ether - hexane (1: $1, v / v)$ as a mobile phase. The band detected at $R f$ value of 0.85 , showing antibacterial activity in TLCbioautography assay, was scraped out and extracted using acetone. After evaporation to dryness (175 mg), the fraction was dissolved in $10 \mathrm{ml}$ of $80 \%$ acetone. The solution was subjected to preparative HPLC (column: Shiseido Capcell Pak C18, $250 \times 10 \mathrm{~mm}$, eluent: $80 \%$ acetone, flow rate: $2 \mathrm{ml} / \mathrm{min}$, monitoring wavelength: $420 \mathrm{~nm}$, column oven: $40^{\circ} \mathrm{C}$ ) to give a crystalline compound (60 mg). The isolated compound was subjected to spectroscopic analyses. The FAB-MS spectrum (JEOL JMS-SX 102A mass spectrometer, positive mode) showed molecular ion related peaks at $\mathrm{m} / \mathrm{z} 190[\mathrm{M}+2 \mathrm{H}]^{+}$, suggesting a reduced type of 
naphthoquinone (Matsuura and Yamaguchi, 1996). From the results of the UV, MS, and NMR analyses, the isolated compound was finally identified as plumbagin (Fig. 3). The chromatographic and spectroscopic analyses of authentic compound also confirmed the structure. The spectroscopic data are as follows: UVvis (benzene); $423 \mathrm{~nm}\left(\mathrm{E}^{1 \%}=38.5\right)$, FAB-MS $(+) ; \mathrm{m} /$ z $190[\mathrm{M}+2 \mathrm{H}]^{+}(100),{ }^{1} \mathrm{H}-\mathrm{NMR}$ (chloroform-d); $\delta$ $2.19\left(3 \mathrm{H}, \mathrm{d}, \mathrm{J}=2.0 \mathrm{~Hz},-\mathrm{CH}_{3}\right), 6.80(1 \mathrm{H}, \mathrm{d}, \mathrm{J}=2.0 \mathrm{~Hz}$, $\mathrm{H}-3), 7.25(1 \mathrm{H}, \mathrm{dd}, \mathrm{J}=2.0,7.5 \mathrm{~Hz}, \mathrm{H}-6), 7.59(1 \mathrm{H}, \mathrm{m}$, $\mathrm{H}-7), 7.62(1 \mathrm{H}, \mathrm{m}, \mathrm{H}-8), 12.0(1 \mathrm{H}, \mathrm{s},-\mathrm{OH}),{ }^{13} \mathrm{C}-\mathrm{NMR}$; $\delta 16.5\left(-\mathrm{CH}_{3}\right), 115.1$ (C-4a), 119.3 (C-8), 124.1 (C6), 132.0 (C-8a), 135.4 (C-3), 136.1 (C-7), 149.6 (C-2), 161.1 (C-5), 184.8 (C-1), 190.3 (C-4).

When the carnivorous plant $D$. muscipula digests insects, the possibility exists that it could become infected by any pathogenic bacteria present in those insects. Instead, the plant appears to absorb the nutrients it requires from the insects that it ingests without becoming infected. Plumbagin may play a role in protecting $D$. muscipula against bacterial pathogens. The results of this study demonstrated the antibacterial activity of plumbagin against food-borne pathogens and other bacteria and suggested that D. muscipula was equipped with a mechanism for preventing infection. Previous reports related to plumbagin in $D$. muscipula have shown that this compound is involved in protecting the plant from herbivores (Tokunaga et al., 2004). In addition, plumbagin has also been shown to inhibit insect molting (Kubo et al., 1983). Plumbagin is also found in other plant taxa, including members of the Plumbaginaceae, such as Plumbago auriculata. It is also used in Africa as a traditional medicine for headaches, vomiting, skin diseases and other problems (Elgorashi et al., 2003) and has been reported in Japanese Diospyros spp. (Ito et al., 1995). Demma et al. (2009) reported that plumbagin induced DNA damage at high concentrations, but showed antigenotoxic effects at low concentrations, and concluded that it was an agent with dual actions. Future studies on this compound, such as quantification studies or studies on its stability and

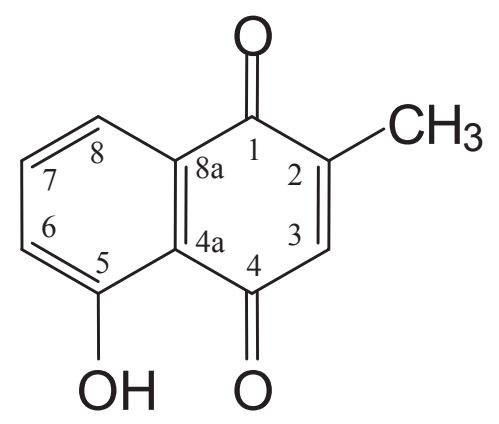

FIG. 3. Chemical structure of plumbagin toxicity, are required to examine its potential application as an antimicrobial agent or repellant.

\section{REFERENCES}

Alzoreky, N. S., and Nakahara, K. (2003) Antibacterial activity of extracts from some edible plants commonly consumed in Asia. Int. J. Food Microbiol., 80, 223-230.

Demma, J., Hallberg, K., and Hellman, B. (2009) Genotoxicity of plumbagin and its effects on catechol and NQNO-induced DNA damage in mouse lymphoma cells. Toxicol. In Vitro, 23, 266-271.

Elgorashi, E. E., Taylor, J. L. S., Maes, A., Staden, J. V., Kimpe, N, D., and Verschaeve, L. (2003) Screening of medicinal plants used in South African traditional medicine for genotoxic effects. Toxicol. Let., 143, 195-207.

Inouye, S., Goi, H., Miyauchi, K., Muraki, S., Ogihara, M., and Iwanami, Y. (1983) Inhibitory effect of volatile constituents of plants on the proliferation of bacteria. Antibacterial activity of plant volatiles. J. Antibact. Antifung. Agents., 11, 609-615.

Ishiguro, Y., Okamoto, K., Sakamoto, H., and Sonoda, Y. (1993) A novel antimicrobial substance in etiolated seedlings of adlay. Biosci. Biotech. Biochem. 57, 866.

Ito, Y., Hayashi, Y., and Kato, A. (1995) Antifungal compounds from trees of the Genus Diospyros with complete assignment of nuclear magnetic resonance data. Mokuzai Gakkaishi., 41, 694-698.

Jayaprakasha, G. K., Selvi, T., and Sakariah, K. K. (2003) Antibacterial and antioxidant activities of grape (Vitis vinifera) seed extracts. Food Res. Int., 36, 117-122.

Juniper, B.E., Robins, R.J., and Joel, D.M. (1989) The carnivorous plants, pp.1-343. Academic Press, San Diego.

Kubo, I., Uchida, M., and Klocke, J. A. (1983). An insect ecdysis inhibitor from the African medicinal plant, Plumbago capensis (Plumbaginaceae); a naturally occurring chitin synthetase inhibitor. Agric. Biol. Chem., 47, 911-913.

Larson, A. E., Yu, R. R. Y., Lee, O, A., Price, S., Haas, G. J., and Johnson, E. A. (1996) Antimicrobial activity of hop extracts against Listeria monocytogenes in media and in Food. Int. J. Food Microbiol., 33, 195-207.

Matsuura, K., and Yamaguchi, I. (1996) FAB, SIMS and FRIT-FAB LC/MS (in Japanese). Kagaku to Seibutsu, 34, pp.116-123.

National Committee for Clinical Laboratory Standards. (1990) Methods for dilution antimicrobial susceptibility tests for bacteria that grow aerobically. Approved standard In NCCLS document M7-A2., 2nd ed. National Committee for Clinical Laboratory Standards, Villanova, Pa.

Negi, P. S., and Jayaprakasha, G. K. (2001) Antibacterial activity of grapefruit (Citrus paradisi) peel extracts. Eur. Food Res. Technol., 213, 484-487.

Negi, P. S., and Jayaprakasha, G. K. (2003) Antioxidant and antibacterial activities of Punica granatum peel extracts. J. Food Sci., 68, 1473-1477.

Nishina, A., and Uchibori, T. (1991) Antimicrobial activity of 2, 6-Dimethoxy-p-benzoquinone, isolated from thickstemmed bamboo, and its analogs. Agric. Biol. Chem., 55, 2395-2398.

Park, B-S., Kim, J-R., Lee, S-E., Kim, K.S., Takeoka, G. R., Ahn, Y-J., and Kim, J-H. (2005) Selective growth-inhibiting effects of compounds identified in Tabebuia impetiginosa inner bark on human intestinal bacteria. J. Agric. Food Chem., 53, 1152-1157.

Toda, M., Oukubo, S., Hiyoshi, R., and Shimamura, T. (1989) 
The bactericidal activity of tea and coffee. Lett. Appl. Microbiol., 8, 123-125.

Tokunaga, T., Takada, N., and Ueda, M. (2004) Mechanism of antifeedant activity of plumbagin, a compound concerning the chemical defense in carnivorous plant. Tetrahedron Lett., 45, 7115-7119.

Vardar-Ünlü, G., Candan, F., Sökmem, A., Daferera, D., Polissiou, M., Sökmen, M., Dönmez, E., and Tepe, B. (2003) Antimicrobial and antioxidant activity of the essential oil and methanol extracts of Thymus pectinatus
Fisch. et Mey. Var. pectinatus (Lamiaceae). J. Agric. Food Chem., 51, 63-67.

Wu, V. C-H., Qiu, X., Bushway, A., and Harper, L. (2008) Antibacterial effects of American cranberry (Vaccinium macrocarpon) concentrate on foodborne pathogens. LWT Food Sci. Technol., 41, 1834-1841.

Yamada, Y., Yamamoto, A., Yoneda, N., and Nakatani, N. (1999) Identification of kaempferol from the leaves of Diospyros kaki and its antimicrobial activity against Streptococcus mutans. Biocontrol Sci., 4, 97-100. 